\title{
DOES A VIRTUAL FUNCTIONAL TRAINING INDUCE CARDIOVASCULAR RESPONSES IN NORMOTENSIVE ADULTS AFTER A SINGLE SESSION AND OVER WEEKS?
}

original paper

(1) University School of Physical Education in Wroclaw

DOI: https://doi.org/10.5114/hm.2019.79732

\author{
JORGE LUIZ DE BRITO-GOMES ${ }^{1,2}$, LEONARDO DOS SANTOS OLIVEIRA ${ }^{3}$, \\ ALESANDRA ARAUJO DE SOUZA ${ }^{4}$, ALINE DE FREITAS BRITO ${ }^{2}$, RAYSA CATARINA \\ CAVALCANTE FIGUEREDO DO MONTE ${ }^{2}$, MANOEL DA CUNHA COSTA ${ }^{2}$ \\ ${ }^{1}$ Collegiate of Physical Education, Vale do São Francisco Federal University, Petrolina, Brazil \\ ${ }^{2}$ Laboratory of Human Performance, State University of Pernambuco, Recife, Brazil \\ ${ }^{3}$ Universidade Estadual de Londrina, Londrina, Brazil \\ ${ }^{4}$ Department of Physical Education, Integrated Colleges of Patos, Patos, Brazil
}

\section{ABSTRACT}

Purpose. Active video games (AVG) provide an attractive alternative to sedentary behaviours and may bring some health benefits. However, single-session and chronic cardiovascular effects of AVG remain unclear. The aim of this study was to verify the impact of single-session and 4-week virtual functional training on cardiovascular responses in normotensive adults. Methods. In a pre-experimental study, 8 university students performed a 30-minute AVG session (Nike Kinect Training ${ }^{\circledR}$ game) at the intensity of $64 \%$ (based on heart rate [HR]) and twice a week for 4 weeks (8 sessions). HR and systolic (SBP) and diastolic (DBP) blood pressure were measured immediately and at 10, 20, and 30 minutes after each session. A generalized estimating equation model and t-test were used to examine changes in cardiovascular responses over time $(p<0.05)$. Effect size was calculated by Cohen's $d$.

Results. A single session did not promote post-exercise hypotension (PEH). However, SBP (6.6-9.0 mm Hg) and DBP (4.5-5.5 mm Hg) decreased in 3/8 and 2/8 sessions, respectively. In pre/post-intervention comparisons at rest, small to large reduction effects were found for $\mathrm{SBP}(-3.0 \mathrm{~mm} \mathrm{Hg}, d=0.3)$, DBP (-4.7 mm Hg, $d=0.6)$, HR (-9 bpm, $d=0.8)$, and double product $(-1389.3 \mathrm{~mm} \mathrm{Hg} \times \mathrm{bpm}, d=1.6)$.

Conclusions. Virtual functional training reduced cardiac workload (chronic effect) and promoted PEH in some sessions among normotensive adults. These findings have practical applications for improving physical activity with attractive exercise forms, which should be recommended for healthy people.

Key words: blood pressure, heart rate, hypotension, video games, physical exertion

\section{Introduction}

Over years, physically inactive video games were used, generally without significant cardiovascular health benefits. On the other hand, active video games (AVG), in which the players have to remain physically active to succeed during matches, help to improve fitness levels and to develop motivation for physical activity $[1,2]$. Several studies with AVG have been carried out in order to verify the improvement of energy expenditure, aerobic capacity, and body composition [2-4]. AVG turn out a practical and attractive way to change sedentary behaviours in different populations [2].

In relation to acute cardiovascular effects, AVG could elicit more energy expenditure and could raise heart rate (HR) and systolic blood pressure (SBP) in children, adolescents, and adults, improving physical activity performance $[3,5]$. Traditional forms of endurance or resistance exercise promote post-exercise hypotension (PEH), which is an important cardiovascular response to exercise, represented by the difference between post- and pre-exercise blood pressure

Correspondence address: Jorge Luiz de Brito-Gomes, Physical Education School, Federal University of São Francisco Valley, Av. José de Sá Maniçoba, S/N - Centro, Petrolina - PE, CEP 56304-917, Brazil, e-mail: jorgelbritog@hotmail.com

Received: September 6, 2018

Accepted for publication: November 14, 2018

Citation: Brito-Gomes JL, Oliveira LS, Souza AA, Brito AF, Monte RCCF, Costa MC. Does a virtual functional training induce cardiovascular responses in normotensive adults after a single session and over weeks?. Hum Mov. 2019;20(2):25-33; doi: https://doi.org/10.5114/hm.2019.79732. 
J.L. Brito-Gomes, L.S. Oliveira, AA. Souza, A.F. Brito, R.C.C.F. Monte, M.C. Costa, Virtual exercise and hypotension

values [6, 7]. PEH has been reported as a decrease in SBP and diastolic blood pressure (DBP), respectively, from 8-10 $\mathrm{mm} \mathrm{Hg}$ and from 3-5 $\mathrm{mm} \mathrm{Hg}$ after aerobic exercise [7] and up to $6 \mathrm{~mm} \mathrm{Hg}$ and $4.7 \mathrm{~mm} \mathrm{Hg}$ after resistance exercises [8, 9].

The results of the published studies on the effects of AVG on cardiovascular responses during and after exercise are still inconclusive [10]. It seems, to this date, that only a study by Rauber et al. [11] evaluated $\mathrm{PEH}$ in 3 random sessions of 30 minutes of a traditional game, AVG, or TV watching, and no statistically significant changes were found over 40 minutes of recovery. In a pre/post-intervention study, Serber et al. [12] observed a reduction in peak HR and resting SBP among middle-aged pre-hypertensive individuals. In turn, Warburton et al. [13], in a 6-week AVG training with 30-minute sessions, and Roopchand-Martin et al. [14], in a 6-week AVG training with 30-60-minute sessions, observed a significant improvement in HR and resting blood pressure in university students.

To our knowledge, no study has performed a combined analysis of acute (during and after sessions) and chronic cardiovascular responses to identify the real scientific benefits of an AVG intervention, once each study uses different AVG. Moreover, to diagnose hypertension and to control it by monitoring blood pressure at home are important [15]. Also, knowing cardiovascular responses during and after exercise is essential to perform a more effective exercise prescription, promoting cardiovascular safety to the practitioners, especially when their clinical condition is associated with high health risks [16].

In view of this background, the aim of this study was to verify single-session and chronic effects of 4 -week virtual functional training with AVG on cardiovascular responses in normotensive adults. Our hypotheses were the following: (a) a single AVG session promotes cardiovascular benefits such as $\mathrm{PEH}$; (b) BP at rest reduces in each session over the weeks; (c) PEH occurs in each session over the weeks; and (d) the virtual functional training reduces $\mathrm{HR}$, SBP, DPB, and double product (DP) at rest after 4 weeks among normotensive adults.

\section{Material and methods}

\section{Participants}

Participants were recruited through an advertisement in social networks and flyers or invitations distributed by the Health Campus of the University of Pernambuco (UPE, Brazil). Young university students, apparently healthy, were selected. The a priori sample size calculation was based on a power $(1-\beta) \geq 0.8$ and an alpha error of 0.05 to detect a mean (standard deviation $[S D]$ ) reduction of 4 (3) $\mathrm{mm} \mathrm{Hg}$ in blood pressure. Power analyses were computed by the $G^{*}$ Power 3.1.9.21 (Franz Faul, Universität Kiel, Germany) for matched pairs difference and a minimum of 7 participants were necessary to carry out the study. Included were normotensive university students of both sexes, aged 18-30 years, apparently healthy (Physical Activity Readiness Questionnaire), and not practising systematized physical activities. Exclusion criteria were the following: disorders limiting the use of AVG (e.g., neurological disorders, physical, visual, or cognitive impairment, deafness, vertigo), specific medical restrictions (e.g., severe pain preventing prescription of selfregulated training, continuous use of medicines), experience in AVG from the Xbox 360 console, less than $85 \%$ attendance to training sessions or having initiated physical exercise programs, occurrence of any osteomyoarticular injury during the study period.

\section{Study design}

A pre-experimental study with repeated measurements was performed in a laboratory with similar temperature conditions $\left(22-24^{\circ} \mathrm{C}\right)$, relative humidity (40-60\%), and atmospheric pressure (ca. $760 \mathrm{~mm} \mathrm{Hg}$ ) across the measurement days. At the first visit, the participants underwent a diagnostic evaluation with risk stratification, anthropometric, cardiovascular, and metabolic measurements, as well as familiarization with the measurement protocol and with the Xbox $360^{\circ}$ console with Kinect in the AVG Nike Kinect Training $^{\circledR}$. After 48 hours, the participants performed a single session (30-minute AVG session) and the acute effects were analysed. After the next 48 hours, the participants followed a 4-week intervention (30-minute AVG sessions, 2 sessions per week); then, the chronic effects were analysed. At the last visit, only cardiovascular resting measurements were performed. Before each session, the participants received task instructions and were given the opportunity to ask any questions. Cardiovascular and perceived exertion measurements were the primary outcomes. The study design is shown in Figure 1.

For all sessions (single session and 8 sessions over weeks), the participants performed cardiovascular resting measurements, followed by an AVG session, and, at the end, reported their perceived exertion. Subsequently, cardiovascular measurements were again performed immediately (P0) and at 10 (P10), 20 (P20), 


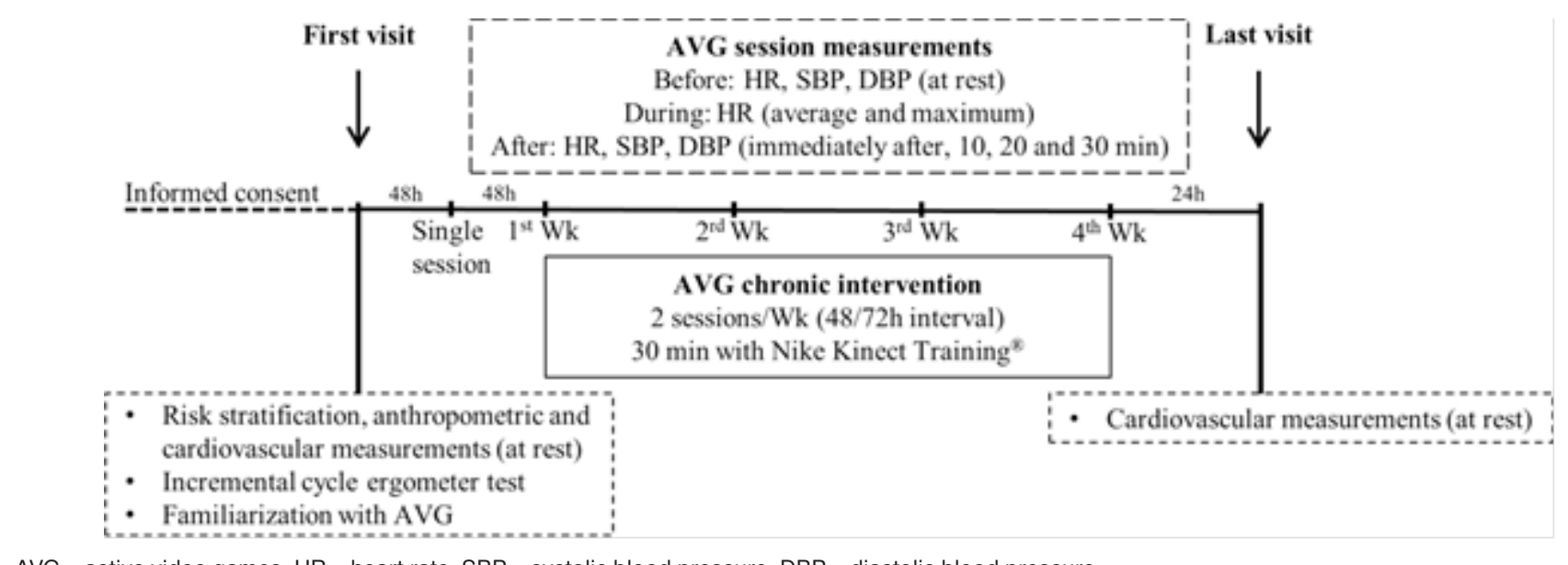

AVG - active video games, HR - heart rate, SBP - systolic blood pressure, DBP - diastolic blood pressure

Figure 1. Study design

and 30 (P30) minutes after exercise. The measurements were performed at the same time of the day in pre/ post-intervention conditions.

In all sessions, the participants used appropriate clothing and footwear to practise physical activity, did not perform moderate or vigorous physical activities in the 24 hours prior to the session, did not intake food at least 2 hours prior to the sessions, and abstained from alcohol and tobacco the day before. All subjects left the laboratory with instructions to maintain their usual activities and not to engage in other physical exercise programs.

\section{Procedures}

\section{Anthropometry}

Body mass, in kilograms, was measured on digital scales (Filizola, Brazil) to the nearest $0.1 \mathrm{~kg}$. Height, in meters, was determined with a wooden stadiometer (Wiso, Brazil), to the nearest $0.1 \mathrm{~cm}$. These measurements were performed by a single trained evaluator, with standardized techniques [17]. Body mass index (weight/height ${ }^{2}$ ) was calculated to characterize the sample.

\section{Metabolic measurements}

Peak oxygen consumption was determined with an incremental test to exhaustion [18] on an electronically braked cycle ergometer (EC-1600 Cateye Ergociser, Cateye, Japan). The participants performed a warm-up on a $25 \mathrm{~W}$ load for 5 minutes. Consequently, the test was initiated with $100 \mathrm{~W}$ for men and $50 \mathrm{~W}$ for women, with an increase of $50 \mathrm{~W}$ for men and $25 \mathrm{~W}$ for women every 2 minutes until voluntary exhaustion.
Voluntary exhaustion was defined as the point at which the participant could no longer maintain the required cadence (50-60 rpm). HR was recorded beat-by-beat by an HR monitor (FT1, Polar, Finland).

The test stopped when at least 2 of the following criteria were met: (a) pedal cadence below $50 \mathrm{rpm}$ for a time greater than 30 seconds; (b) self-reported sensation of localized muscle pain that would disrupt the continuation of the test; (c) reaching $\geq 95 \%$ of maximal HR predicted by age (210 - age).

\section{Cardiovascular measurements}

HR was determined with an electronic monitor (FT1, Polar, Finland) at rest and during exercise, when the mean and maximal $\mathrm{HR}$ values were reached. SBP and DBP were measured on the left arm with an automatic upper arm blood pressure monitor (HEM 7113, Omron, Japan) at rest, immediately after exercise, and at 10, 20, and 30 minutes after exercise. A single investigator performed all the measurements in the study. Resting measurements were taken with the participant sitting on a chair with back support for 10 minutes, feet on the ground, and the blood pressure monitor positioned at heart level. The left arm and right arm were checked on the first day of evaluation for standardization of the arm with higher pressure, as recommended by the $7^{\text {th }}$ Brazilian Guideline of Arterial Hypertension [19]. DP was calculated as $\mathrm{SBP} \times \mathrm{HR}(\mathrm{mm} \mathrm{Hg} \times \mathrm{bpm})$, providing valuable information about the cardiac workload and myocardial oxygen demand. Session intensity was determined from average, maximal, and resting HR [20]. 
J.L. Brito-Gomes, L.S. Oliveira, AA. Souza, A.F. Brito, R.C.C.F. Monte, M.C. Costa, Virtual exercise and hypotension

\section{Rating of perceived exertion}

Rating of perceived exertion (RPE) was verified at the end of each session with the 6-20 Borg scale printed on A4 paper, in the original size, in accordance with the recommendations [21]. The Borg scale was presented in front of the participants, who verbally determined their perception of general physical exertion on the basis of cardiovascular (tachycardia/bradycardia), respiratory (hyper-/hypoventilation), and muscular (general muscular pain/fatigue) sensations. The procedure had been duly explained to each participant before the beginning of the session.

\section{Video, audio, and video game console systems}

The video system was set with a multimedia projector (PowerLite S10+, Epson, China) attached to the ceiling of the lab and connected to the console projecting an image $130 \mathrm{~cm}$ high by $160 \mathrm{~cm}$ wide (ca. 82 inches). The audio system consisted of a $30 \mathrm{~W}$ amplified sound box (OCM 126 professional, Oneal, Brazil) connected to the console. The Xbox Kinect ${ }^{\mathrm{TM}}$ (Xbox 360, Microsoft, USA) console with Nike Kinect Training ${ }^{\circledR}$ game was used.

In order to get closer to the actual practice of physical exercises, the authors chose an AVG that had characteristics of functional training, as it is used in real life and has been applied in previous studies [2]. The structured Nike Kinect Training ${ }^{\circledR}$ game at the beginning and at the end of the session performs joint mobility to assist in the warm-up while providing functional movements such as squatting, pushing, jumping, forward, sideways, and backward, as presented in the literature [2]. The amount, duration, and speed of the exercises, as well as the interval were proposed by a 'functional physical evaluation' (ca. 20 minutes) of the game itself before the first session. The sessions increased or decreased the intensity depending on the amount of movement presented by each participant.

\section{Statistical analysis}

Normality was confirmed by the Shapiro-Wilk test for pre- and post-exercise SBP, DBP, DP, and resting HR values. SBP and DBP were presented as mean and 95\% confidence interval (CI). Resting HR, average and maximal HR, and RPE were reported as median and interquartile range. A generalized estimating equation model with link function and appropriate distribution was used to examine changes in SBP and DBP over time (single session and $1^{\text {st }}$ to $8^{\text {th }}$ sessions) and within each session (at rest, immediately post-exercise - P0, 10 minutes after - P10, 20 minutes after - P20, and 30 minutes after - P30) with sequential Bonferroni for multiple comparisons. A correlation matrix with the smallest quasi-likelihood under independence model criterion (QIC) value was chosen as the preferred correlation structure. Average and maximal HR and RPE values were compared among sessions with Friedman's test and Dunn's post-hoc test. Paired $t$-test was used to evaluate differences between pre/post-intervention values for HR and DP at rest. Effect size was calculated with Cohen's $d$ statistics (with the use of pre-intervention $S D$ ) with the Psychometrica calculator. The values of $d<0.20$ were considered a trivial effect, 0.20-0.59 - small, 0.60-1.19 - moderate, 1.20-1.99 - large, and $\geq 2.0$ - very large effect [22]. In addition, the two-way mixed model intra-class correlation coefficient $\left(\mathrm{ICC}_{3,1}\right)$ and standard error of measurement $\left(\mathrm{SEM}=S D_{\text {pool }} \times \sqrt{1-I C C}\right)$ were calculated to estimate minimum detectable difference (MDD) for blood pressure values (pre/post) as follows: $\mathrm{MDD}=$ $\mathrm{SEM} \times 1.96 \times \sqrt{2 \cdot(95 \% C I)})$. The level of significance was set at $p<0.05(\alpha=0.05)$. The data were analysed by the IBM SPSS Statistics 25.0 software.

\section{Ethical approval}

The research related to human use has been complied with all the relevant national regulations and institutional policies, has followed the tenets of the Declaration of Helsinki, and has been approved by the Ethics Committee of the University of Pernambuco in accordance with the National Health Council (No. 577.277/2014).

\section{Informed consent}

Informed consent has been obtained from all individuals included in this study.

\section{Results}

The participants completed all training sessions and performed AVG sessions at the intensity of $63.7 \%$ $(S D=5.8, \min =56.6 \%, \max =71.1 \%)$. The demographic and baseline characteristics of the participants are presented in Table 1 .

Table 2 displays SBP and DBP resting and postexercise values at each session. Resting values for SBP were similar across sessions $(p>0.05)$. A single session did not promote PEH $(p>0.05)$, although SBP $(7.0-8.0 \mathrm{~mm} \mathrm{Hg})$ and DBP $(4.0-8.0 \mathrm{~mm} \mathrm{Hg})$ reductions were greater than the MDD for both blood pressure values. Immediately after exercise, SBP was higher 
Table 1. Characteristics of normotensive adults before the active video game intervention $(n=8)$

\begin{tabular}{lc}
\hline Variables & Mean $(S D)^{*}$ \\
\hline Age (years) & $23(6)$ \\
Body weight $(\mathrm{kg})$ & $67.5(10.7)$ \\
Height $(\mathrm{m})$ & $1.69(0.1)$ \\
Body mass index $\left(\mathrm{kg} / \mathrm{m}^{2}\right)$ & $23.7(1.9)$ \\
Resting heart rate $(\mathrm{bpm})$ & $78(10)$ \\
Systolic blood pressure $(\mathrm{mm} \mathrm{Hg})$ & $109(13)$ \\
Diastolic blood pressure $(\mathrm{mm} \mathrm{Hg})$ & $71(9)$ \\
Maximal workload $(\mathrm{W})$ & $135.7(67.5)$ \\
\hline
\end{tabular}

$S D$ - standard deviation

* There were no significant differences between sexes $(p>0.05)$.

than the rest in the $4^{\text {th }}(\Delta=+13.5 \mathrm{~mm} \mathrm{Hg} ; p=0.001)$, $5^{\text {th }}(\Delta=+13.4 \mathrm{~mm} \mathrm{Hg} ; p=0.001), 6^{\text {th }}(\Delta=+13.5 \mathrm{~mm} \mathrm{Hg}$; $p=0.001), 7^{\text {th }}(\Delta=+14.0 \mathrm{~mm} \mathrm{Hg} ; p=0.001)$, and $8^{\text {th }}$ $(\Delta=+15.4 \mathrm{~mm} \mathrm{Hg} ; p=0.003)$ sessions. In the $3^{\text {rd }}$ session, SBP was lower than the rest compared with 10 $(\Delta=-7.6 \mathrm{~mm} \mathrm{Hg} ; p=0.002)$ and 30 minutes $(\Delta=$
$-6.6 \mathrm{~mm} \mathrm{Hg} ; p=0.001)$. In the $6^{\text {th }}$ session, SBP was lower than the rest compared with 30 minutes $(\Delta=$ $-7.0 \mathrm{~mm} \mathrm{Hg} ; p=0.016)$. In the $8^{\text {th }}$ session, SBP was lower than the rest after $20(\Delta=-7.6 \mathrm{~mm} \mathrm{Hg} ; p=0.040)$ and $30(\Delta=-9.0 \mathrm{~mm} \mathrm{Hg} ; p=0.003)$ minutes.

DBP at rest was similar across sessions $(p>0.05)$ (Table 2). In the $3^{\text {rd }}$ session, DBP was lower than rest after 30 minutes $(\Delta=-4.5 \mathrm{~mm} \mathrm{Hg} ; p=0.049)$. In the $7^{\text {th }}$ session, DBP was lower than the rest after 20 minutes $(\Delta=-5.5 \mathrm{~mm} \mathrm{Hg} ; p=0.022)$.

Rest HR in the $8^{\text {th }}$ session was lower than in the $1^{\text {st }}$ $(\Delta=+14 \mathrm{bpm} ; p=0.001), 2^{\text {nd }}(\Delta=+14 \mathrm{bpm} ; p=0.001)$, $3^{\text {rd }}(\Delta=+14 \mathrm{bpm} ; p=0.001)$, and $4^{\text {th }}(\Delta=+14 \mathrm{bpm}$; $p=0.001)$ sessions. In addition, resting HR in the $7^{\text {th }}$ session was lower than in the $1^{\text {st }}$ session $(\Delta=+14 \mathrm{bpm}$; $p=0.001)$. Average $\left(\chi_{(7)}^{2}=11.6 ; p>0.05\right)$ and maximal $\left(\chi_{(7)}^{2}=11.5 ; p>0.05\right) \mathrm{HR}$ or $\operatorname{RPE}\left(\chi_{(7)}^{2}=5.7 ; p>0.05\right)$ did not change over the sessions (Table 3 ).

In the pre/post-intervention comparisons, large and moderate effects were found for DP and HR, respectively. DP $(\Delta=-1389.3 \mathrm{~mm} \mathrm{Hg} \times \mathrm{bpm} ; p=0.001 ; d=$

Table 2. Systolic (SBP) and diastolic (DBP) blood pressure (mm Hg) of normotensive adults at rest and post-exercise in each AVG session $(n=8)$

\begin{tabular}{|c|c|c|c|c|c|c|}
\hline Session & $\begin{array}{c}\text { Blood } \\
\text { pressure }\end{array}$ & Rest & $\mathrm{P} 0$ & P10 & P20 & P30 \\
\hline \multirow{2}{*}{$\begin{array}{l}\text { Single } \\
\text { session }\end{array}$} & SBP & $114(101-127)$ & 133 (116-140) & 119 (98-135) & $106(98-115)$ & 107 (95-115) \\
\hline & DBP & $74(57-90)$ & $70(64-75)$ & $66(60-75)^{\#}$ & $65(55-73)^{\#}$ & $66(55-72)^{\#}$ \\
\hline \multirow{2}{*}{$1^{\text {st }}$} & SBP & 109 (100-117) & 119 (113-124) & $102(95-110)$ & 105 (101-110) & 105 (100-110) \\
\hline & DBP & $71(66-77)$ & $68(64-72)$ & $64(58-70)^{\#}$ & $65(61-69)^{\#}$ & $66(61-72)^{\#}$ \\
\hline \multirow{2}{*}{$2^{\text {nd }}$} & SBP & $110(103-116)$ & 117 (113-121) & 108 (105-112) & 107 (104-109) & $108(102-114)$ \\
\hline & DBP & $71(66-77)$ & $68(63-73)$ & $66(62-71)^{\#}$ & $64(63-60)^{\#}$ & $65(63-71)^{\#}$ \\
\hline \multirow{2}{*}{$3^{\text {rd }}$} & SBP & 109 (104-115) & 115 (110-120) & $102(96-107)^{*}$ & 104 (100-107) & $103(99-106)^{*}$ \\
\hline & DBP & $70(64-76)$ & $65(62-69)$ & $64(60-69)^{\#}$ & $64(62-67)^{\#}$ & $65(62-68)^{* \#}$ \\
\hline \multirow{2}{*}{$4^{\text {th }}$} & SBP & 107 (100-114) & $120(115-126)^{*}$ & 108 (102-115) & 105 (103-108) & 103 (99-106) \\
\hline & DBP & $66(62-71)$ & $68(64-73)$ & $67(64-70)$ & 66 (62-69) & 65 (62-69) \\
\hline \multirow{2}{*}{$5^{\text {th }}$} & SBP & 109 (102-116) & $122(116-129)^{*}$ & $112(106-117)$ & $104(101-107)$ & $105(100-110)$ \\
\hline & $\mathrm{DBP}$ & $71(65-76)$ & $66(63-69)$ & $66(63-69)^{\#}$ & $64(62-67)^{\#}$ & $65(62-67)^{\#}$ \\
\hline \multirow{2}{*}{$6^{\text {th }}$} & SBP & 109 (103-116) & $123(114-132)^{*}$ & $111(107-115)$ & 107 (103-110) & $102(99-106)^{*}$ \\
\hline & $\mathrm{DBP}$ & $71(67-76)$ & $66(63-70)$ & $66(63-69)^{\#}$ & $68(65-70)$ & 67 (64-70) \\
\hline \multirow{2}{*}{$7^{\text {th }}$} & SBP & $110(102-118)$ & $124(116-133)^{*}$ & 107 (103-112) & $106(102-111)$ & $104(101-107)$ \\
\hline & $\mathrm{DBP}$ & $69(67-74)$ & $69(64-74)$ & $66(62-69)$ & $63(61-66)^{* \#}$ & $63(61-65)^{\#}$ \\
\hline \multirow{2}{*}{$8^{\text {th }}$} & SBP & $110(105-115)$ & $125(116-135)^{*}$ & $108(104-113)$ & $102(97-108)^{*}$ & $100(98-104)^{* \#}$ \\
\hline & DBP & $68(64-72)$ & $64(61-68)$ & $66(62-70)$ & $63(60-67)^{\#}$ & $63(60-66)^{\#}$ \\
\hline
\end{tabular}

Data presented as mean and 95\% confidence interval. P0 - immediately post-exercise, P10 - after 10 minutes,

P20 - after 20 minutes, P30 - after 30 minutes

* significant difference from rest $(p<0.05)$

\# greater than the minimum detectable difference for SBP $(8.5 \mathrm{~mm} \mathrm{Hg})$ and/or for DBP (5.0 $\mathrm{mm} \mathrm{Hg})$ 
J.L. Brito-Gomes, L.S. Oliveira, AA. Souza, A.F. Brito, R.C.C.F. Monte, M.C. Costa, Virtual exercise and hypotension

Table 3. Resting, maximal, and average heart rate (bpm) and rating of perceived exertion (6-20 Borg scale) of normotensive adults in each AVG session $(n=8)$

\begin{tabular}{lcccc}
\hline Session & Resting HR & Maximal HR & Average HR & RPE \\
\hline Acute session & $78(10)$ & $193(13)$ & $126(10)$ & $15(1)$ \\
$1^{\text {st }}$ & $79(16)^{* * *}$ & $179(8)$ & $144(21)$ & $15(4)$ \\
$2^{\text {nd }}$ & $77(14)^{* *}$ & $176(23)$ & $143(25)$ & $15(4)$ \\
$3^{\text {rd }}$ & $79(18)^{* *}$ & $174(17)$ & $142(16)$ & $14(3)$ \\
$4^{\text {th }}$ & $79(6)^{* *}$ & $175(16)$ & $145(27)$ & $14(4)$ \\
$5^{\text {th }}$ & $72(13)$ & $181(21)$ & $140(20)$ & $13(5)$ \\
$6^{\text {th }}$ & $72(14)$ & $186(18)$ & $149(8)$ & $14(2)$ \\
$7^{\text {th }}$ & $69(14)$ & $177(22)$ & $133(10)$ & $13(2)$ \\
$8^{\text {th }}$ & $69(11)$ & $183(36)$ & $145(11)$ & $12(2)$ \\
\hline
\end{tabular}

Data presented as median and interquartile range. HR - heart rate, RPE - rating of perceived exertion

* significant difference from the $7^{\text {th }}$ session $(p<0.05)$

** significant difference from the $8^{\text {th }}$ session $(p<0.05)$

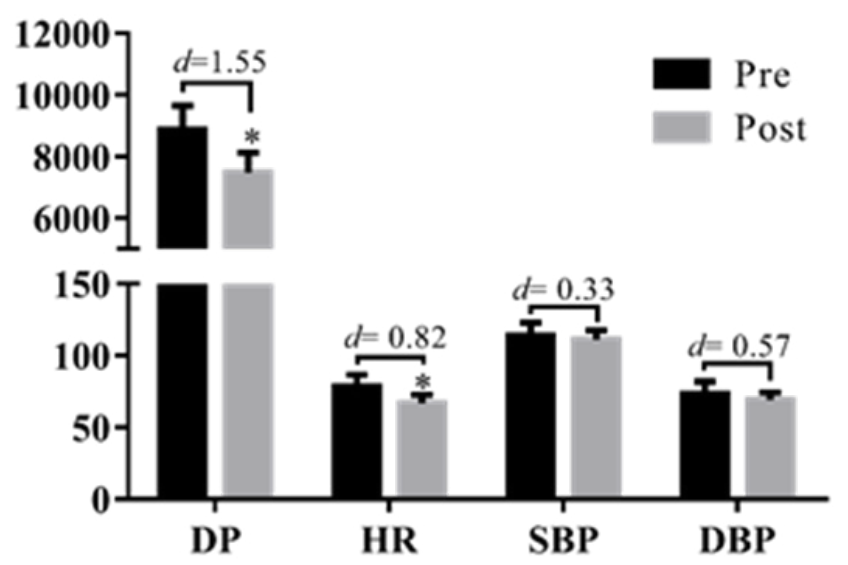

* significant difference from pre-intervention $(p<0.05)$ $d$-Cohen's effect size

Figure 2. Double product (DP), heart rate (HR), systolic (SBP) and diastolic (DBP) blood pressure pre- and post-AVG intervention values at rest in normotensive adults $(n=8)$. Data presented as mean and $95 \%$ confidence interval

1.55) and $\operatorname{HR}(\Delta=-8.5 \mathrm{bpm} ; p=0.001 ; d=0.82)$ at rest were reduced after the 4 -week AVG intervention. SBP $(\Delta=-3.0 \mathrm{~mm} \mathrm{Hg} ; p=1.000 ; d=0.33)$ and $\mathrm{DBP}(\Delta=$ $-4.7 \mathrm{~mm} \mathrm{Hg} ; p=0.062 ; d=0.57$ ) presented only small effects in the pre/post-intervention comparisons (Figure 2).

\section{Discussion}

This study investigated cardiovascular responses following single-session and 4-week functional training in an active virtual environment with Nike Kinect Training $^{\circledR}$ game by an Xbox Kinect ${ }^{\mathrm{TM}}$ in normotensive adults. The main findings indicated that (a) a single
AVG session did not promote $\mathrm{PEH}$, refuting the first hypothesis; (b) BP at rest did not reduce in each session over the weeks, refuting the second hypothesis; (c) SBP and DBP decreased after exercise in 3/8 and $2 / 8$ sessions of virtual functional training, respectively, confirming partially the third hypothesis; and (d) DP and HR at rest presented large and moderate reduction effects, respectively, in the pre/post-intervention comparisons, confirming partially the last hypothesis. Thus, AVG intervention reduced cardiac workload (pre/post-intervention); however, the hypotensive postexercise effect was only observed in some sessions.

Previous studies have reported that a single AVG session induces a significant increase in HR, SBP, DBP, and hence in DP $[1,2,4,5,23]$. However, the PEH phenomenon in relation to AVG remains unclear. Our research is pioneering in investigating the cardiovascular importance of practising virtual functional exercise for the clinical effects on HR and blood pressure control among normotensive adults. Systolic and diastolic hypotension after a 30-minute AVG session was compatible with values observed after 30-45 minutes of moderate traditional aerobic exercises [12]. Systolic hypotension greater than the calculated MDD was detected only in the last AVG session but diastolic hypotension greater than the calculated MDD was identified in $7 / 8$ sessions.

MDD was used to define the amount of change in a variable that must be achieved to reflect a true difference [24]. The American College of Sports Medicine argues that a mere decrease of $2 \mathrm{~mm} \mathrm{Hg}$ is enough to reduce the occurrence of stroke by $14-17 \%$ and the risk of coronary artery disease by $6-9 \%$ [25]. These data reinforce our findings about the importance of the practice of functional training in a virtual environment; besides the physical and psychological benefits, 
AVG can be an important tool to improve the blood pressure profile of normotensive adults, also keeping them physically active.

Rauber et al. [26] evaluated healthy adolescents' $\mathrm{PEH}$ during 40 minutes of recovery after 3 random sessions of 30 minutes of traditional games (PLAY: run and catch, dodgeball, and capture the flag), AVG (Dance Dance Revolution), and watching TV. SBP and DBP increased significantly in all conditions during the sessions. However, the magnitude of blood pressure response was significantly lower in the PLAY setting compared with AVG or TV after sessions. In a similar population to that in our study, female university students performed a 6-week training (30-60 minutes of Just Dance 4 game sessions) and, unlike our participants, reduced resting blood pressure [14]. Likewise, Warburton et al. [13] identified a reduction in resting SBP of approximately $9 \mathrm{~mm} \mathrm{Hg}$ among college boys who underwent a 30-minute AVG session (Cyclebike) for 6 weeks. Furthermore, pre-hypertensive middleaged adults performed a 12 -week training with Nintendo Wii games and a reduction in resting SBP and HR after the intervention was observed [12].

In our study, the absence of a statistically significant reduction in resting SBP could be explained by the fact that the participants were normotensive, with no need for physiological changes in order to reduce SBP. Moreover, after comparison with similar studies [12-14, $23,26]$, it is conjectured that the type of AVG seems to have a strong influence, considering that each has its own characteristics of prescription, also in normotensive people. Nonetheless, our results indicated that the practice of virtual functional training for normotensive adults seems to have an influence on the cardiovascular effects at the central nervous system level.

Since SBP represents the highest values during ventricular contraction [27], this type of exercise seems to be not sufficient to change cardiovascular inotropic components, but only the chronotropic components, as it was perceived through the HR behaviour. In fact, resting HR presented significant reduction after our intervention; hence, the decrease of DP, also observed after the intervention, was dependent on the HR changes. Other studies also investigated the influence of AVG modalities on cardiovascular fitness by identifying a resting HR reduction [12-14].

A significant diastolic hypotension was verified at 20 $\left(7^{\text {th }}\right.$ session) and at 30 ( $3^{\text {rd }}$ session) minutes of recovery, and the MDD of $5 \mathrm{~mm} \mathrm{Hg}$ was found in several moments (10, 20 and 30 minutes) of AVG sessions and in almost all sessions over the weeks. Considering that DBP represents the behaviour of peripheral resistance or the ease of blood flow from the arterioles into the capillaries [27], it is believed that virtual functional training appears to be more clinically beneficial at the peripheral level. Then, each training session may have influenced vascular relaxation mediated by blood flow.

A possible explanation may be the training intensity, which in our study remained in the range of $56-71 \%$ of the maximum HR, since it is already known that acute exercise sessions performed with light to moderate intensity can promote increased shear stressmediated vasodilation, which results in significant reductions in blood pressure. Indeed, in studies that identified significant reductions in blood pressure at rest, regardless of the type of AVG, their intensities ranged from $40 \%$ to $75 \%$ of maximum $\operatorname{HR}[13,25]$. In turn, this increase in cardiovascular and metabolic demand has an influence on PEH and the reduction of blood pressure. Rauber et al. [11] observed a decrease of DBP, not only in a single session but also throughout all training sessions at almost all moments related to rest.

The chronic effect on blood pressure in physical exercise decreases from 1.2 to $16.8 \mathrm{~mm} \mathrm{Hg}$ in SBP and from 3.0 to $16.5 \mathrm{~mm} \mathrm{Hg}$ in DBP. These data have been previously reported by Cornelissen and Fagard [8]. In the present study, small effects on blood pressure were observed after a 4-week AVG intervention, whereas there was resting bradycardia as a chronic effect of the intervention. Even if HR is a commonly measured clinic variable in response to vascular effects, most studies record it at rest and during AVG sessions as a tool to determine the intensity of the games [1, 2, 23].

A major decrease in blood pressure occurred in DP, which is a variable associated to the myocardial oxygen demand and cardiac work [28]. Considering that DP depends on HR and SBP, and that SBP remained unchanged, it is suggested the AVG intervention induced stress on heart with low overload on blood pressure status. As there is no evidence in the literature that analysed this variable in a pre/post-intervention setting yet, our study provides the first confirmation that regular practice of functional training is able to significantly reduce DP in a virtual environment, which is directly linked to the safety of physical exercise practice [29].

Since the study consisted of a play of a virtual functional exercise at a moderate intensity for 30 minutes twice a week over 4 weeks in a laboratory setting, our findings should be generalized with caution. Although our data are relevant to the research lines that involve cardiovascular responses to AVG, they are subject to limitations. The first one was lack of traditional func- 
J.L. Brito-Gomes, L.S. Oliveira, AA. Souza, A.F. Brito, R.C.C.F. Monte, M.C. Costa, Virtual exercise and hypotension

tional training sessions (control group) to compare with AVG, preferably in a controlled clinical trial to confirm our results. Secondly, to broaden the PEH analysis, blood pressure verification could be performed for more than 30 minutes after the video game matches. Therefore, future research is needed to extend these findings.

\section{Conclusions}

A 4-week virtual functional training with AVG at moderate intensity presented large reduction effects on cardiac workload (pre/post-intervention) and promoted PEH, in some sessions, among normotensive adults. These findings have practical applications for improving physical activity with attractive exercise forms for healthy people.

\section{Acknowledgments}

This study was financed in part by the Coordenação de Aperfeiçoamento de Pessoal de Nível Superior (CAPES) in Brasília, Finance Code 001.

\section{Disclosure statement}

No author has any financial interest or received any financial benefit from this research.

\section{Conflict of interest}

The authors state no conflict of interest.

\section{References}

1. Brito-Gomes JL, Perrier-Melo RJ, Oliveira SFM, Guimarães FJSP, Costa MC. Physical effort, energy expenditure, and motivation in structured and unstructured active video games: a randomized controlled trial. Hum Mov. 2016;17(3):190-198; doi: 10.1515/humo2016-0021.

2. Brito-Gomes JL, Perrier-Melo RJ, Wikstrom EA, Costa MC. Improving aerobic capacity through active videogames: a randomized controlled trial. Motriz: Rev Educ Fis. 2015;21(3):305-311; doi: 10.1590/S198065742015000300012 .

3. Brito-Gomes JL, Perrier-Melo RJ, Oliveira SFM, Costa MC. Exergames can be tool to increase physical activity and better physical conditioning? [in Portuguese]. Braz J Phys Act Health. 2015;20(3):232-242; doi: 10.12820/rbafs.v.20n3p232.

4. Clevenger KA, Howe CA. Energy cost and enjoyment of active videogames in children and teens: Xbox 360 Kinect. Games Health J. 2015;4(4):318-324; doi: 10.1089/g4h.2014.0101.

5. Taylor LM, Maddison R, Pfaeffli LA, Rawstorn JC, Gant N, Kerse NM. Activity and energy expenditure in older people playing active video games. Arch Phys
Med Rehabil. 2012;93(12):2281-2286; doi: 10.1016/j. apmr.2012.03.034.

6. Brito LC, Queiroz AC, Forjaz CL. Influence of population and exercise protocol characteristics on hemodynamic determinants of post-aerobic exercise hypotension. Braz J Med Biol Res. 2014;47(8):626-636; doi: 10.1590/1414-431X20143832.

7. Kenney MJ, Seals DR. Postexercise hypotension. Key features, mechanisms, and clinical significance. Hypertension. 1993;22(5):653-664; doi: 10.1161/01.HYP.22. 5.653.

8. Cornelissen VA, Fagard RH. Effect of resistance training on resting blood pressure: a meta-analysis of randomized controlled trials. J Hypertens. 2005;23(2):251-259; doi: 10.1097/00004872-200502000-00003.

9. Meneses J Junior, Brito Gomes JL, Gomes JP, Amaral MRA, Madruga RSL, Silva TB, et al. Hemodynamic response during and after Pilates session in comparison of aerobic and resistance exercise [in Portuguese]. Braz J Phys Act Health. 2014;19(6):732-743; doi: 10.12820/ rbafs.v.19n6p732.

10. Ruivo JA. Exergames and cardiac rehabilitation: a review. J Cardiopulm Rehabil Prev. 2014;34(1):2-20; doi: 10.1097/HCR.0000000000000037.

11. Rauber SB, Boullosa DA, Carvalho FO, de Moraes JF, de Sousa IR, Simões HG, et al. Traditional games resulted in post-exercise hypotension and a lower cardiovascular response to the cold pressor test in healthy children. Front Physiol. 2014;5:235; doi: 10.3389/ fphys.2014.00235.

12. Serber ER, Ciccolo J, Palmer K, Cobb V, Tilkemeier PL, Bock BC. The feasibility of exercise videogames for cardiovascular risk reduction among adults: a pilot for "Wii heart fitness". J Sports Med Phys Fitness. 2016; 56(3):319-327.

13. Warburton DE, Bredin SS, Horita LT, Zbogar D, Scott JM, Esch BT, et al. The health benefits of interactive video game exercise. Appl Physiol Nutr Metab. 2007;32(4): 655-663; doi: 10.1139/H07-038.

14. Roopchand-Martin S, Nelson G, Gordon C, Sing SY. A pilot study using the XBOX Kinect for exercise conditioning in sedentary female university students. Technol Health Care. 2015;23(3):275-283; doi: 10.3233/ THC-150899.

15. Póvoa TIR, Jardim TV, Carneiro CdS, Ferreira VR, Mendonça KL, Morais PRS, et al. Home blood pressure monitoring as an alternative to confirm diagnoses of hypertension in adolescents with elevated office blood pressure from a Brazilian state capital. Arq Bras Cardiol. 2017;109(3):241-247; doi: 10.5935/abc.20170114.

16. Thompson PD, Franklin BA, Balady GJ, Blair SN, Corrado D, Estes NA, et al. Exercise and acute cardiovascular events placing the risks into perspective: a scientific statement from the American Heart Association Council on Nutrition, Physical Activity, and Metabolism and the Council on Clinical Cardiology. Circulation. 2007;115(17):2358-2368; doi: 10.1161/CIRCULATIONAHA.107.181485. 
17. Marfell-Jones MJ, Stewart AD, Olds T, Ridder JH. International standards for anthropometric assessment. Wellington: International Society for the Advancement of Kinanthropometry; 2012.

18. Astrand PO, Ryhming I. A nomogram for calculation of aerobic capacity (physical fitness) from pulse rate during sub-maximal work. J Appl Physiol. 1954;7(2):218221; doi: 10.1152/jappl.1954.7.2.218.

19. Malachias MVB, Gomes MAM, Nobre F, Alessi A, Feitosa AD, Coelho EB. $7^{\text {th }}$ Brazilian Guideline of Arterial Hypertension. Chapter 2: Diagnosis and classification. Arq Bras Cardiol. 2016;107(3 Suppl. 3); doi: 10.5935/abc.20160152.

20. Skinner JS. Exercise testing and exercise prescription for special cases: theoretical basis and clinical application. Baltimore: Lippincott Williams \& Wilkins; 2005.

21. Borg G. Borg's perceived exertion and pain scales [in Portuguese]. São Paulo: Manole; 2000.

22. Hopkins WG, Marshall SW, Batterham AM, Hanin J. Progressive statistics for studies in sports medicine and exercise science. Med Sci Sports Exerc. 2009;41(1): 3-13; doi: 10.1249/MSS.0b013e31818cb278.

23. Brito-Gomes JL, Oliveira LS, Perrier-Melo RJ, Santos JNC, Guimarães FJSP, Costa MC. Acute intensity and motivation to play: comparison of structured and unstructured active video games - a pilot study. Int Phys Med Rehab J. 2018;3(1):79-83; doi: 10.15406/ipmrj. 2018.03.00080.

24. Portney LG, Watkins MP. Foundations of clinical research: applications to practice, $3^{\text {rd }}$ ed. Philadelphia: F.A. Davis Company; 2015.

25. Pescatello LS, Franklin BA, Fagard R, Farquhar WB, Kelley GA, Ray CA, et al. American College of Sports Medicine position stand. Exercise and hypertension. Med Sci Sports Exerc. 2004;36(3):533-553.

26. Rauber SB, Carvalho FO, Sousa IRC, Mazzoccante RP, Franco CBS, Farias DL, et al. Cardiovascular responses during and after active VIDEO GAME and television [in Portuguese]. Motriz: Rev Educ Fis. 2013;19(2):358367; doi: 10.1590/S1980-65742013000200013.

27. MacDonald JR. Potential causes, mechanisms, and implications of post exercise hypotension. J Hum Hypertens. 2002;16(4):225-236; doi: 10.1038/sj.jhh.1001377.

28. Hermida RC, Fernández JR, Ayala DE, Mojón A, Alonso I, Smolensky M. Circadian rhythm of double (ratepressure) product in healthy normotensive young subjects. Chronobiol Int. 2001;18(3):475-489; doi: 10.1081/ CBI-100103970.

29. Gobel FL, Norstrom LA, Nelson RR, Jorgensen CR, Wang Y. The rate-pressure product as an index of myocardial oxygen consumption during exercise in patients with angina pectoris. Circulation. 1978;57(3):549-556; doi: 10.1161/01.CIR.57.3.549. 